\title{
STUDI PERILAKU ETIS WIRANIAGA
}

\author{
Anas Hidayat \\ Fakultas Ekonomi Universitas Islam Indonesia \\ e-mail: hidayatanas@yahoo.com \\ Santi Budiman \\ STIE-IEU Yogyakarta
}

\begin{abstract}
This research aims to test 1) the influence of rewards and control to sales force ethical behavior, 2) the influence of sales force ethical behavior to role conflict, performance and job satisfaction. Respondents of the research represent the automotive sales force at central java. This research adopts the instruments that are developed by Roman and Munuera (2005). Sample selection is performed based on purposive sampling. 212 respondents have fulfilled questionaires completely. The analysed use the path analysis. Result of research indicate that there are influence of rewards and control toward sales force ethical behavior. Findings also show that there are influence of ethical behavior toward role conflict and performance. However, there are no significance influence of ethical behavior toward job satisfaction as well as there are no significance influence of role conflict to job satisfaction.
\end{abstract}

Keywords: Reward, Control, Ethical behavior, Role conflict, Performance, Satisfaction, Sales force

\begin{abstract}
Abstraksi
Penelitian ini bertujuan menguji 1) pengaruh kompensasi dan pengawasan terhadap perilaku etis wiraniaga, 2) pengaruh perilaku etis wiraniaga terhadap konflik peran, kinerja dan kepuasan kerja, dan 3) pengauh konflik peran terhadap kepuasan kerja. Responden dalam penelitian ini wiraniaga perusahaan otomotif di Jawa Tengah. Metode pengambilan sampel dilakukan dengan metode purposive sampling, 212 responden berhasil dikumpulkan dalam penelitian ini. Data dikumpulkan menggunakan kuesioner. Penelitian ini mengadopsi instrumen yang dikembangkan oleh Roman dan Munuera (2005). Analisis data menggunakan analisis jalur. Hasil penelitian ini menunjukkan bahwa ada pengaruh yang signifikan kompensasi dan pengawasan terhadap perilaku etis wiraniaga. Hasil penelitian juga menunjukkan adanya pengaruh yang signifikan perilaku etis wiraniaga terhadap konflik peran dan kinerja. Tidak terdapat pengaruh yang signifikan perilaku etis wiarniaga terhadap kepuasan kerja. Hasil penelitian juga menunjukkan tidak ada pengaruh yang signifikan dari konflik peran terhadap kepuasan kerja.
\end{abstract}

Kata kunci: Kompensasi, Pengawasan, Perilaku etis, Konflik peran, Kinerja, Kepuasan kerja, Wiraniaga.

\section{PENDAHULUAN}

Masalah etika usaha semakin meningkat bukan hanya di Indonesia, tetapi juga di negara-negara lain termasuk di negara-negara maju. Hal ini ditunjukan dengan survey yang dilakukan oleh Sales \& Marketing Management pada sejumlah manajer pemasaran yang melakukan pelanggaran etika (Roman and Munuera, 2005). Perhatian mengenai masalah etika pemasaran tidak terlepas dari semakin berkembangnya dunia usaha namun juga tuntutan dari kalangan akademisi pemasaran. Kegiatan pemasaran yang makin merebak baik di dalam maupun di luar negeri, telah menimbulkan tantangan baru, yaitu adanya tuntutan praktek yang etis, yang juga menjadi tuntutan kehidupan bisnis di berbagai negara. Transparansi ekonomi global menuntut praktik pemasaran yang etis. Praktik berusaha yang tidak etis dapat mengurangi produktivitas dan mengekang efisiensi (Karta- 
sasmita, 1997). Dampak lain dari perilaku pemasaran yang tidak etis adalah risiko perusahaan kehilangan pelanggan (Roman and Munuera, 2005).

Kemajuan ekonomi mendorong munculnya pelaku bisnis baru sehingga menimbulkan persaingan bisnis. Semua usaha bisnis tersebut berusaha untuk memperoleh keuntungan yang sebesar-besarnya. Namun terkadang untuk mencapai tujuan itu, segala upaya dan tindakan dilakukan walaupun pelaku bisnis harus melakukan tindakan-tindakan yang mengabaikan berbagai dimensi moral dan etika bisnis itu sendiri, termasuk etika dalam pemasaran produk. Untuk mengantisipasi hal itu, maka perlu diidentifikasi faktor-faktor pembentuk etika (Purnamasari dan Chrismastuti, 2006).

Permasalahan etika pemasaran merupakan bagian dari topik penelitian bisnis seperti yang dilakukan oleh Roman and Munuera (2005), Abratt et al. (1999), dan Schwepker (2001). Topik mengenai etika pemasaran sering dihubungkan dengan konsumen dan perilaku wiraniaga sebagai wakil dari perusahaan. Wiraniaga merupakan bagian atau perwakilan dari perusahaan yang berhubungan atau kontak langsung dengan konsumen. Wiraniaga merupakan pekerjaan yang berhubungan dengan etika dalam berbisnis. Perilaku etis wiraniaga merupakan perilaku wiraniaga yang berorientasi etis dalam berhubungan dengan konsumen. Wiaraniaga yang baik harus memiliki sifat-sifat etis dalam aktivitas pemasaran (Herche et al., 1996).

Etika wiraniaga menjadi bahan utama dalam penelitian pemasaran karena memiliki relevansi terhadap tujuan jangka panjang perusahaan (Abratt and Penman, 2002). Untuk contoh, berdasarkan survey Sales \& Marketing Management dari 200 manajer pemasaran, 49 persen menyatakan wiraniaga merek berbohong mengenai aktivitas penjualan, 34 persen menyatakan wiraniaganya membuat perjanjian jual-beli yang tidak terealisasi dan 22 persen menyatakan telah menjual produk yang tidak dibutuhkan konsumen (Marchetti, 1997). Ada beberapa alasan mengenai fokus penelitian pada perilaku etika wiraniaga. Pekerjaan wiraniaga lebih erat hubungannya dengan etika dibandingkan pekerjaan lainnya. Pekerjaan wiraniaga relatif tanpa pengawasan; wiraniaga bertanggung jawab secara umum terhadap penjualan perusahaan, sehingga mereka cenderung stress karena dinilai berdasarkan ukuran jangka pendek (Wotruba, 1990). Beberapa penelitian menunjukkan bahwa perilaku etika wiraniaga penting dalam menjaga hubungan jangka panjang dengan konsumen (Boedecker et al., 1991). Faktor penentu dan dampak perilaku etika wiraniaga penting untuk menjaga tujuan jangka panjang perusahaan.

Penelitian mengenai perilaku etika wiraniaga pernah dilakukan oleh Roman and Munuera (2005), Abratt et al. (1999), Schwepker (2003). Hasil penelitian Roman and Munuera (2005) menunjukkan bahwa sistem kompensasi, sistem pengawasan, usia mempengaruhi perilaku etis wiraniaga sedangkan pendidikan tidak berpengaruh signifikan terhadap perilaku etis wiraniaga, hasil penelitian juga menunjukkan adanya pengaruh perilaku etis wiraniaga terhadap konflik peran secara internal dan kepuasan kerja namun perilaku etis wiraniaga tidak berpengaruh terhadap kinerja wiraniaga. Penelitian tersebut menggunakan sampel wiraniaga yang berasal dari perusahaan jasa keuangan. Keterbatasan jenis industri yang digunakan merupakan kelemahan dalam penelitian tersebut, sehingga hasil penelitian ini tidak dapat digeneralisasi pada industri lainnya, namun penggunaan hanya satu jenis industri merupakan kelebihan penelitian ini sehingga hasilnya tidak bias.

Penelitian ini mereplikasi penelitian Roman and Munuera (2005) dengan dikondisikan di Indonesia. Replikasi bertujuan memberikan bukti empiris dan konfirmasi konsistensi dengan hasil penelitian sebelumnya. Perbedaan kondisi dan wilayah menyebabkan adanya perbedaan budaya sehingga interpretasi responden mengenai nilai-nilai etika yang dianut juga berbeda. Indonesia termasuk negara Asia yang sering menghadapi permasalahan etika, contohnya Hidayat (2010) dalam penelitiannya mengindikasikan tingginya perilaku yang berkaitan dengan konsumsi produk bajakan.

Relevansi hasil penelitian terdahulu tidak dapat digeneralisasi di Indonesia karena perbedaan nilai etika di negara barat dengan negara timur terutama Asia. Perbedaan nilai dan budaya di negara barat dan asia menjadikan konteks penelitian bersifat konfirmatory atas penelitian terdahulu. Permasalahan etika pemasaran yang timbul dalam etika wiraniaga di Indonesia menjadikan konteks penelitian ini 
menarik untuk diteliti kembali di Indonesia. Penelitian ini dibatasi pada bidang otomotif untuk menghindari perbedaan karakteristik wiraniaga berdasarkan perbedaan jenis usaha. Penelitian yang dilakukan bertujuan menguji pengaruh kompensasi, dan pengawasan terhadap perilaku etis wiraniaga, serta menguji pengaruh perilaku etis wiraniaga terhadap konflik peran internal, kinerja dan kepuasan kerja wiraniaga.

\section{KAJIAN PUSTAKA DAN HIPOTESIS}

\section{Pengaruh Kompensasi Terhadap Etika}

Beberapa penelitian menunjukkan bahwa kompensasi dan pengawasan merupakan faktor yang mempengaruhi perilaku wiraniaga. Cravens et al. (1993), Honeycutt et al., (2001) dan Oliver and Anderson (1994) menemukan kompensasi dan pengawasan berpengaruh signifikan terhadap penjualan wiraniaga. Hal ini bertentangan dengan penelitian Kurland (1996) yang menemukan kompensasi dan pengawasan tidak berpengaruh signifikan terhadap perilaku etis wiraniaga.

Kompensasi merupakan pemicu langsung yang memotivasi perilaku individu dalam mencapai tujuan perusahaan. Perencanaan kompensasi disusun untuk meningkatkan penjualan wiraniaga di masa mendatang. Tindakan tidak etis ditunjukkan dengan gejala untuk tidak bertindak etis. Pemberian imbalan atau tunjangan akan meningkatkan kinerja pegawai karena imbalan atau tunjangan akan mendorong pegawai untuk bertindak secara etis. Roman and Munuera (2004) dalam penelitian juga menemukan bahwa semakin baik kompensasi yang diberlakukan dalam organisasi akan meningkatkan etika wiraniaga. Hal ini berarti semakin baik kompensasi maka semakin baik perilaku etis wiraniaga. Dengan demikian hipotesis yang diajukan sebagai berikut:

H1: Semakin baik kompensasi maka semakin baik perilaku etis wiraniaga.

\section{Pengaruh Pengawasan Terhadap Etika}

Roman and Munuera (2005) menemukan bahwa pengawasan dalam suatu organisasi akan mempengaruhi tindakan etis wiraniaganya. Dengan pengawasan, kesempatan bagi wiraniaga untuk berperilaku tidak etis menjadi kecil karena wiraniaga mempertimbangkan konsekuensi dari perilaku tidak etisnya. (Robertson and Anderson, 1993; Verbeke et al., 1996).

Pemikiran setiap wiraniaga berbeda tergantung pada pengawasan yang ada (Oliver and Anderson, 1994). Pengawasan merupakan sejumlah prosedur yang digunakan untuk mengawasai, mengarahkan, mengevaluasi serta sebagai kebijakan dalam pemberian kompensasi bagi wiraniaga. Dengan demikian semakin baik pelaksanaan pengawasan maka semakin baik perilaku etis wiraniaga. Hunt and Vasquez-Parraga (1993) mengindikasikan bahwa manfaat pengawasan adalah mengembangkan dan memperbaiki budaya organisasi yang meningkatkan perilaku etis dan mengurangi perilaku tidak etis. Hal ini berarti semakin baik pengawasan maka semakin baik perilaku etis wiraniaga. Dengan demikian hipotesis yang diajukan sebagai berikut:

$\mathrm{H} 2$ : Semakin baik pengawasan maka semakin baik perilaku etis wiraniaga.

\section{Pengaruh Perilaku Etis Terhadap Konlik Peran}

Konflik peran didefinisikan sebagai konflik yang timbul dalam diri wiraniaga yang disebabkan masalah pengambilan keputusan pada beberapa kepentingan yang berbeda yaitu konsumen dan perusahaan. Perusahaan cenderung memberikan target penjualan bagi wiraniaga sedangkan konsumen berkeinginan memperoleh produk yang berkualitas serta bermanfaat sesuai harapan mereka. Seorang wiraniaga cenderung mengabaikan kepentingan konsumen dengan tujuan untuk mencapai target penjualan. Chonko and Burnett (1983) secara empiris menemukan perilaku etis wiraniaga akan mengurangi konflik peran bagi wiraniaga, berbeda dengan penelitian Dubinsky and Ingram (1984) yang menemukan bahwa perilaku etis wiraniaga tidak berhubungan dengan konflik peran bagi wiraniaga. Turner and Valentine (2001), menemukan bahwa sikap sinis dari customer service dan wiraniaga berhubungan positif dengan konflik peran. Seorang wiraniaga memiliki kewajiban untuk memenuhi harapan konsumen dan perusahaan, namun hal tersebut sering bertentangan sehingga timbul konflik peran dalam diri wiraniaga. Saat wiraniaga tidak berperilaku etis, maka konsumen akan menolak pembelian 
karena memiliki image negatif pada produk yang ditawarkan (Boyle and Dwyer, 1995). Roman and Munuera (2005) menemukan bahwa perilaku etis wiraniaga akan mengurangi konflik peran dalam diri wiraniaga. Dengan demikian semakin tinggi perilaku etis wiraniaga maka semakin rendah konflik peran yang diarasakan wiraniaga. Dengan demikian hipotesis yang diajukan dalam penelitian ini sebagai berikut:

H3: Semakin baik perilaku etis wiraniaga maka semakin rendah konflik peran yang diarasakan wiraniaga.

\section{Pengaruh Perilaku Etis Terhadap Kinerja}

Kinerja merupakan hasil dari perilaku wiraniaga. Wiraniaga yang sukses memiliki orientasi pada konsumen dan membangun kepercayaan dari konsumen (Schiffman, 2004). Beberapa penelitian menunjukkan bahwa perilaku etis wiraniaga berhubungan positif dengan kepuasan dan kepercayaan konsumen sehingga membentuk hubungan jangka panjang dengan konsumen yang menguntungkan wiraniaga (Roma'n and Ruiz, 2005). Konsumen melakukan transaksi berdasarkan kepercayaan mereka. Dengan membangun hubungan dengan konsumen melalui perilaku etis akan meningkatkan transaksi sehingga kinerja wiraniaga akan meningkat. Dengan demikian dapat disimpulkan wiraniaga yang berorientasi etis, kinerjanya akan meningkat sebagai dampak dari hubungan jangka panjang dengan konsumen (Roman and Munuera, 2005).

Weeks and Nantel (1992) menemukan bahwa wiraniaga yang mengerti kebijkan etika perusahaan lebih sukses dalam pekerjaaan mereka. Honeycutt et al. (1995) menemukan bahwa wiraniaga yang memiliki kinerja tinggi berorientasi etis dan Ingram et al. (2001) secara empiris menemukan wiraniaga yang memiliki itikad moral berhubungan positif dengan kinerja. Valentine (2001) menemukan bahwa perilaku etis wiraniaga berhubungan langsung dengan kinerja wiraniaga namun Roman and Munuera (2005) menemukan perilaku etis wiraniaga tidak berhubungan langsung dengan kinerja wiraniaga. Dengan demikian hipotesis yang diajukan dalam penelitian ini sebagai berikut:

H4: Semakin baik perilaku etis wiraniaga maka semakin tinggi kinerja wiraniaga.

\section{Pengaruh Perilaku Etis Terhadap Kepuasan Kerja}

Penelitian Weeks and Nantel (1992) dan Schwepker (2001) menunjukkan bahwa iklim etika akan mempengaruhi kepuasan kerja wiraniaga. Penelitian Beatty et al. (1996) juga menemukan hal yang sama yaitu wiraniaga yang berorientasi etis cenderung puas dengan pekerjaan mereka. Wiraniaga yang berperilaku etis akan puas dengan pekerjaan mereka karena menjaga interkasi dengan konsumen (Ingram et al., 2001), Perilaku etis akan membnetuk citra positif bagi wiraniaga sehingga cenderung dipercaya dan dihormati sehingga timbul kepuasan dalam diri mereka. Hal ini didukung dengan hasil penelitian Roman and Munuera (2005) yang menemukan perilaku etis wiraniaga berhubungan positif dengan kepuasan kerja wiraniaga. Dengan demikian semakin tinggi perilaku etis wiraniaga maka semakin tinggi kepuasan kerja wiraniaga. Dengan demikian hipotesis yang diajukan sebagai berikut: H5: Semakin baik perilaku etis wiraniaga maka semakin tinggi kepuasan kerja wiraniaga.

\section{Pengaruh Konflik Peran Terhadap Kepuasan Kerja Wiraniaga}

Konflik peran memiliki hubungan yang negatif dengan kepuasan kerja (Mackenzie et al., 1998). Johnston et al., (1990) menemukan bahwa kepuasan kerja tidak berhubungan signifikan dengan konfli peran dalam diri wiraniaga. Wiraniaga yang mengalami konflik akan menimbulkan kecemasan dan gangguan secara emosional yang berdampak pada kepuasan (Churchill et al., 1976). Roman and Munuera (2005) menemukan bahwa semakin tinggi konflik peran dalam diri wiraniaga maka semkian rendah kepuasan kerjanya, sebaliknya semakin rendah konflik peran yang diarasakan wiraniaga maka semakin tinggi kepuasan kerjanya. Dengan demikian hipotesis yang diajukan dalam penelitian ini sebagai berikut:

H6: Semakin rendah konflik peran wiraniaga maka semakin tinggi kepuasan kerja wiraniaga.

Secara skematis hubungan variabel dalam penelitian ini digambarkan dalam model sebagai berikut: 


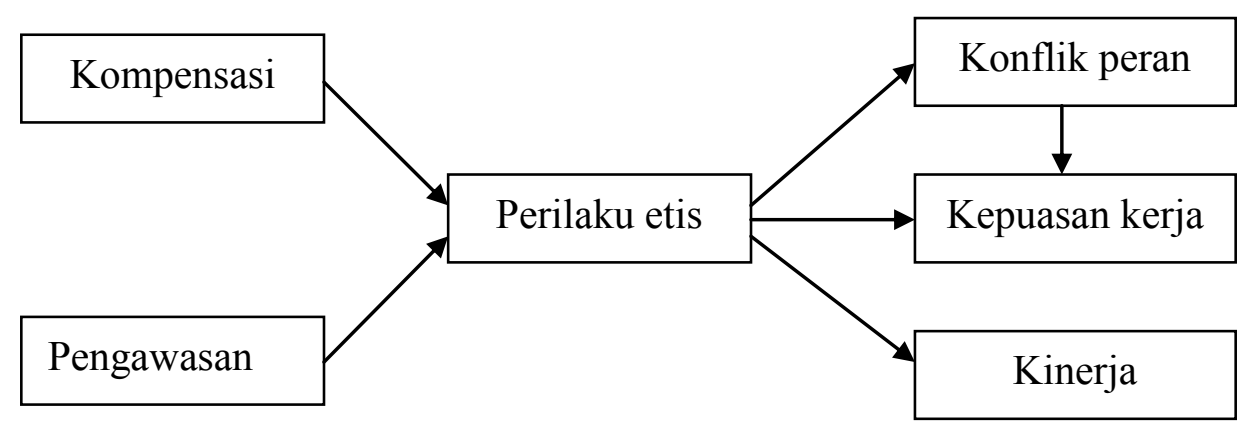

Sumber: Diadaptasi dari Roman and Munuera (2005)

Gambar 1: Model Penelitian

\section{METODE PENELITIAN}

Desain penelitian (research design) merupakan rerangka kerja atau cetak biru yang bertujuan sebagai pedoman utama dalam melakukan seluruh rangkaian kegiatan penelitian (Sekaran, 2003). Perspektif keterlibatan peneliti mempengaruhi variabel sehingga penelitian ini merupakan penelitian expost facto. Penelitian ini didasarkan pada pengujian hipotesis (hyphotesis testing) sehingga disebut dengan penelitian kausal dan survey berdasarkan metode pengumpulan data.

Populasi dalam penelitian ini adalah wiraniaga perusahaan otomotif di Jawa Tengah. Metode pengambilan sampel dilakukan dengan metode non-probability sampling khususnya metode purposive sampling dengan kriteria wiraniaga perusahaan otomotif yang telah bekerja minimal 3 tahun dengan pertimbangan memiliki pengalaman yang cukup di bidangnya. Jumlah sampel dalam penelitian ini berjumlah 212 yang memenuhi kaidah pengujian multivariat yaitu $25 \mathrm{x}$ jumlah variabel independen.

Data yang digunakan dalam penelitian ini adalah sumber data primer yang diperoleh dari penyebaran instrumen penelitian atau kuesioner. Instrumen yang digunakan diadaptasi dari Roman and Munuera (2005) yang diukur dengan 5 skala Likert, yang nilainya dimulai dari angka 1 = sangat tidak setuju sampai dengan angka $5=$ sangat setuju.

Definisi operasional masing-masing variabel tersebut adalah sebagai berikut (Roman and Munuera, 2003):

Perilaku etis wiraniaga yaitu perilaku wiraniaga yang berorientasi etis pada konsumen yang diukur dengan norma kejujuran, fairness (keadilan) dan keterbukaan (full disclosure) dalam penjualan produk. Kompensasi merupakan gaji yang direkomendasikan perusahaan saat wiraniaga perusahaan berorientasi jangka panjang dan bertanggung jawab dalam merealisasikan penjualan secara adil yang diukur dengan keadilan, kesesuaian, dan kewajaran kompensasi. Pengawasan adalah sejumlah prosedur dari organisasi dalam mengawasi, mengarahkan, dan mengevaluasi wiraniaga melalui pengawasan langsung dan tidak langsung supervisor, arahan supervisor, dan sanksi pelanggaran. Konflik internal yang dimaksud adalah konflik yang dirasakan oleh wiraniaga yang disebabkan keinginan memenuhi dua atau lebih harapan baik dari konsumen maupun dari perusahaan yang diukur dengan perbedaan tuntutan kepentingan perusahaan dan konsumen, pekerjaan dan hati nurani, dan dilema pengambilan keputusan. Kepuasan kerja wiraniaga adalah kepuasan pada seluruh karakteristik internal dan eksternal yang wiraniaga rasakan meliputi kepuasan profesi, kepuasan bekerja dan kepuasan di lingkungan kerja. Kinerja yang dimaksud adalah pencapaian hasil yang diperoleh wiraniaga meliputi target penjualan, dan pengembangan pangsa pasar.

\section{Validitas dan Reliabilitas Instrumen Peneli- tian}

Pengujian validitas instrumen dilakukan dengan menggunakan factors analysis. Sebuah faktor disebut valid apabila memiliki factor loading berada pada kisaran $0.40 \mathrm{ke}$ atas (Sekaran, 2003). Pengujian validitas instrumen penelitian menggunakan berdasarkan nilai corrected aitem total correlation menunjukkan semua aitem valid. Pengujian reliabilitas instrumen dilakukan dengan menggunakan croncbach alpha dengan rule of thumb nilai 0,6 (Sekaran, 2003) Hasil uji reliabilitas variabel menunjukkan kisaran Alpha sebesar 0,6670,947. Hasil uji validitas dan reliabilitas sebagai berikut: 
Tabel 1: Uji Validitas Aitem dan Internal Consistency Reliability

\begin{tabular}{cccc}
\hline Variabel & $\begin{array}{c}\text { Corrected item to total } \\
\text { Correlation }\end{array}$ & Alpha if item deleted & $\begin{array}{c}\text { Koefisien Cronbach } \\
\text { Alpha }\end{array}$ \\
\hline Perilaku etis & 0,6462 & 0,8060 & 0,826 \\
EB1 & 0,8250 & 0,6066 & \\
EB2 & 0,6992 & 0,7448 & 0,857 \\
EB3 & 0,7308 & 0,8021 & \\
Kompensasi & 0,8531 & 0,6774 & \\
R1 & 0,6316 & 0,8178 & 0,947 \\
R1 & & & \\
R1 & 0,8760 & 0,9367 & \\
Pengawasan & 0,8003 & 0,9454 & \\
C1 & 0,8735 & 0,9371 & 0,847 \\
C2 & 0,8760 & 0,9367 & \\
C3 & 0,7785 & 0,9488 & \\
C4 & 0,8750 & 0,9370 & \\
C5 & & & \\
C6 & 0,8312 & 0,6953 & \\
Konlik peran & 0,7875 & 0,8407 & \\
RC1 & 0,7750 & 0,7361 & \\
RC2 & & & \\
RC3 & 0,5693 & 0,4384 & \\
Kinerja & 0,6484 & 0,3280 & \\
P1 & 0,6563 & 0,5414 & \\
P2 & & & \\
P3 & 0,5183 & 0,6351 & \\
Kepuasan kerja & 0,4156 & 0,6924 & \\
JS1 & 0,4964 & 0,6501 & \\
JS2 & 0,5999 & 0,5884 & \\
JS3 & & & \\
JS4 & & & \\
\hline
\end{tabular}

Sumber: Data primer diolah, 2012

\section{Metode Analisis Data}

Metode analisis yang digunakan adalah analisis jalur (path analysis).

\section{HASIL ANALISIS DAN PEMBAHASAN}

Hasil uji kesesuaian model menggunakan chisquare, CMIN/DF, GFI, AGFI, RMSEA, TLI, dan CFI diringkas sebagaimana tampak pada tabel 2. Tabel 2 menunjukkan bahwa model penelitian secara keseluruhan fit. Secara keseluruhan nilai Chi square dengan probabilitas sebesar 0,062 >0,05 menunjukkan keseluruhan model fit (Overall goodness-of-fit). Tingkat signifikan penerimaan yang direkomendasikan adalah apabila $\mathrm{p} \geq 0,05$ yang berarti matriks input sebenarnya dengan matriks input yang diprediksi tidak berbeda secara statistik (Ghozali, 2004). Selain itu setelah diuji kecocokannya nilai RMSEA, TLI, dan CFI dibandingkan nilai acuan (cut off value) persamaan model struktural hasilnya baik, kecuali GFI dan AGFI yang masih di bawah nilai kriteria namun dapat ditoleransi secara umum.

Secara skematis hasil analisis jalur ditunjukkan oleh gambar 2 berikut:

Tabel 2: Hasil Goodness of Fit Model Pengukuran

\begin{tabular}{lccc}
\hline \multicolumn{1}{c}{ Indeks } & Cut off Value & Hasil & Evaluasi Model \\
\hline Chi square & Mendekati 0 & 9,832 & Baik \\
Probability & $\geq 0,05$ & 0,062 & Baik \\
GFI & $\geq 0,90$ & 0,685 & Marginal \\
AGFI & $\geq 0,90$ & 0,848 & Marginal \\
RMSEA & $\leq 0,08$ & 0,039 & Baik \\
TLI & $\geq 0,90$ & 0,915 & Baik \\
CFI & $\geq 0,90$ & 0,904 & Baik \\
\hline
\end{tabular}

Sumber: Data primer diolah, 2012 


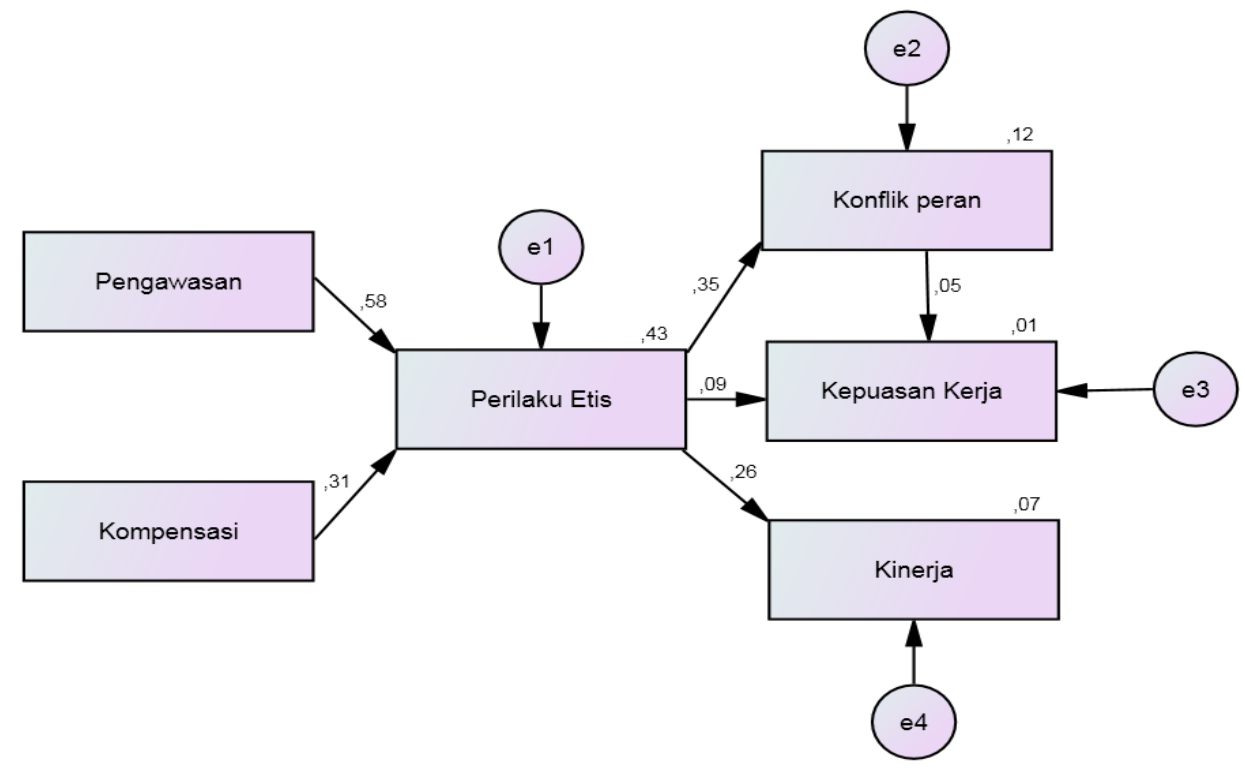

Gambar 2: Hasil Analisis Jalur

Tabel 3: Evaluasi Bobot Regresi Uji Kausalitas

\begin{tabular}{lcccccc}
\hline & Variabel & Estimasi & S.E. & C.R. & P \\
\hline Perilaku Etis & $\leftarrow$ & Pengawasan &, 428 &, 050 & 8,632 & $* * *$ \\
Perilaku Etis & $\leftarrow$ & Kompensasi &, 244 &, 052 & 4,662 & $* * *$ \\
Konflik Peran & $\leftarrow$ & Perilaku Etis &, 439 &, 104 & 4,209 & $* * *$ \\
Kepuasan Kerja & $\leftarrow$ & Perilaku Etis &, 100 &, 110 &, 912 &, 362 \\
Kinerja & $\leftarrow$ & Perilaku Etis &, 348 &, 113 & 3,095 &, 002 \\
Kepuasan Kerja & $\leftarrow$ & Konflik Peran &, 046 &, 088 &, 529 &, 597 \\
\hline
\end{tabular}

Keterangan: ${ }^{* * *}: 0,000$

Hasil bobot regresi antarvariabel yang sering disebut sebagai estimasi loading factors atau lambda value dapat digunakan untuk menganalisis uji kausalitas variabel. Berdasarkan signifikansi nilai CR (Critical Ratio) dengan nilai probabilitas $(p)=0.05$. Hasil bobot regresi uji kausalitas disajikan pada tabel 3 .

Penjelasan lebih lanjut analisis evaluasi bobot regresi tersebut dapat diuraikan dan dijelaskan uji hipotesis sebagai berikut ini, Variabel kompensasi mempengaruhi perilaku etis wiraniaga secara signifikan dengan tingkat signifikansi sebesar 0,000 lebih kecil dari nilai probabilitas $\leq 0,05$ yang berarti hipotesis 1 diterima. Variabel pengawasan mempengaruhi perilaku etis wiraniaga secara signifikan dengan tingkat signifikansi sebesar 0,000 lebih kecil dari nilai probabilitas $\leq 0,05$ yang berarti hipotesis 2 diterima. Variabel perilaku etis mempengaruhi konflik peran secara signifikan dengan tingkat signifikansi sebesar 0,000 lebih kecil dari nilai probabilitas $\leq 0,05$, dengan demikian hipotesis 3 diterima. Variabel perilaku etis mempengaruhi kinerja secara signifikan dengan tingkat signifikansi sebesar 0,002 lebih kecil dari nilai probabilitas $\leq 0,05$ yang berarti hipotesis 4 diterima. Variabel perilaku etis tidak mempengaruhi kepuasan kerja secara signifikan dengan tingkat signifikansi sebesar 0,362 lebih besar dari nilai probabilitas $>0,05$ yang berarti hipotesis 5 ditolak. Variabel konflik peran tidak mempengaruhi kepuasan kerja secara signifikan dengan tingkat signifikansi sebesar 0,529 lebih besar dari nilai probabilitas $>0,05$ sehingga hipotesis 6 ditolak.

Besarnya pengaruh masing-masing variabel secara langsung (standardized direct effect) maupun tidak langsung (standardized indirect effect) diringkas dalam tabel sebagai berikut: 
Tabel 4: Efek Langsung, dan Efek Tidak Langsung

\begin{tabular}{lcc}
\hline \multicolumn{1}{c}{ Variabel } & Efek langsung & Efek tidak langsung \\
\hline Kompensasi $\rightarrow$ Perilaku etis & 0,312 & - \\
Pengawasan $\rightarrow$ Perilaku etis & 0,578 & - \\
Kompensasi $\rightarrow$ Konflik peran & - & 0,109 \\
Pengawasan $\rightarrow$ Konflik peran & - & 0,202 \\
Kompensasi $\rightarrow$ Kepuasan kerja & - & 0,032 \\
Pengawasan $\rightarrow$ Kepuasan kerja & - & 0,060 \\
Kompensasi $\rightarrow$ Kinerja & - & 0,083 \\
Pengawasan $\rightarrow$ Kinerja & - & 0,153
\end{tabular}

Sumber: Data diolah, 2012

Besarnya pengaruh masing-masing variabel secara langsung (standardized direct effect) maupun tidak langsung (standardized indirect effect) (standardized total effect) menunjukkan bahwa pengawasan memiliki pengaruh sebesar 0,578 terhadap perilaku etis wiraniaga, lebih besar pengaruhnya dibandingkan kompensasi sebesar 0,578. Nilai pengawasan secara menyeleurh memiliki pengaruh yang lebih besar secara tidak langsung terhadap konflik peran, kepuasan kerja dan kinerja dibandingkan kompensasi.

Hasil temuan dalam pengujian hipotesis1 dan 2 konsisten dengan hasil penelitian Roman and Munuera (2004) yang menemukan bahwa semakin baik sistem kompensasi yang diberlakukan dalam organisasi akan meningkatkan etika wiraniaga. Sistem kompensasi merupakan pemicu langsung yang memotivasi perilaku individu dalam mencapai tujuan perusahaan. Perencanaan kompensasi disusun untuk meningkatkan penjualan wiraniaga di masa mendatang. Tindakan tidak etis ditunjukkan dengan gejala untuk tidak bertindak etis atau sensitivitas etis dalam bekerja.

Roman and Munuera (2005) juga menemukan bahwa sistem pengawasan dalam suatu organisasi akan mempengaruhi tindakan etis wiraniaganya. Sistem pengawasan merupakan tindakan yang digunakan untuk mengawasi, mengarahkan, mengevaluasi serta sdebagai kebijakan dalam pemberian kompensasi bagi wiraniaga. Dengan sistem pengawasan, kesempatan bagi wiraniaga untuk berperilaku tidak etis menjadi kecil karena mereka mempertimbangkan konsekuensi dari perilaku tidak etisnya. (Robertson and Anderson, 1993; Verbeke et al., 1996). Hunt and Vasquez-Parraga (1993) mengindikasikan bahwa manfaat sistem pengawasan adalah mengembangkan dan memperbaiki budaya organisasi yang meningkatkan perilaku etis dan mengurangi perilaku tidak etis.

Temuan dalam pengujian hipotesis 3 didasari oleh kecenderungan wiraniaga mengabaikan kepentingan konsumen dengan tujuan untuk mencapai target penjualan. Seorang wiraniaga memiliki kewajiban untuk memenuhi harapan konsumen dan perusahaan, namun hal tersebut sering bertentangan sehingga timbul konflik peran dalam diri wiraniaga. Saat wiraniaga tidak berperilaku etis, maka konsumen akan menolak pembelian karena memiliki image negatif pada produk yang ditawarkan (Boyle and Dwyer, 1995). Hasil konsisten dengan penelitain Roman and Munuera (2005) yang menemukan bahwa perilaku etis wiraniaga akan mengurangi onflik peran dalam diri wiraniaga.

Hasil temuan dalam pengujian hipotesis 4 tidak konsisten dengan hasil penelitian Roman and Munuera (2005) yang menemukan perilaku etis wiraniaga tidak berhubungan langsung dengan kinerja wiraniaga. Wiraniaga yang sukses memiliki orientasi pada konsumen dan membangun kepercayaan dari konsumen (Schiffman, 2004). Menurut Roman and Munuera (2005) wiraniaga di Spanyol cenderung berperilaku tidak etis untuk meningkatkan komisi yang ingin diperoleh. Hal ini merupakan dorongan dari produsen agar wiraniaga meningkatkan penjualan tanpa memperhatikan etika. Selain itu perilaku etis merupakan hubungan kepercayaan yang bersifat jangka panjang antara wiraniaga dengan konsumen sedangkan kinerja wiraniaga diukur dengan penjualan jangka pendek. Di Indonesia, konsumen melakukan transaksi berdasarkan kepercayaan mereka. Dengan membangun 
hubungan dengan konsumen melalui perilaku etis akan meningkatkan transaksi sehingga kinerja wiraniaga akan meningkat. Dengan demikian dapat disimpulkan wiraniaga yang berorientasi etis, kinerjanya akan meningkat sebagai dampak dari hubungan jangka panjang dengan konsumen (Roman and Munuera, 2005). Weeks and Nantel (1992) menemukan bahwa wiraniaga yang mengerti kebijakan etika perusahaan lebih sukses dalam pekerjaaan mereka.

Hasil temuan dalam hipotesis 5 tidak konsisten dengan penelitian Roman and Munuera (2005) yang menemukan perilaku etis wiraniaga berhubungan positif dengan kepuasan kerja wiraniaga. Menurut Roman and Munuera (2005), wiraniaga yang etis dalam bekerja cenderung lebih sukses dibanding yang tidak etis. Etika merupakan ukuran kesuksesan yang berdampak pada kepuasan kerja. Di Asia, kepuasan kerja tidak hanya oleh perilaku etis namun oleh beberapa faktor lain seperti karakteristik pekerjaan, kompensasi, hubungan pimpinan dengan bawahan, karir dan promosi serta hubungan dengan rekan kerja.

Hasil temuan dalam penelitian konsisten dengan penelitian Johnston et al. (1990) yang menemukan bahwa kepuasan kerja tidak berhubungan signifikan dengan konflik peran dalam diri wiraniaga. Penelitian ini tidak konsisten dengan penelitian Roman and Munuera (2005) yang menemukan bahwa semakin tinggi konflik peran dalam diri wiraniaga maka semakin rendah kepuasan kerjanya, sebaliknya semakin rendah konflik peran yang dirasakan wiraniaga maka semakin tinggi kepuasan kerjanya. Dalam penelitian ini, perilaku etis tidak mempengaruhi konflik peran maupun kepuasan kerja, dengan demikian wiraniaga kurang mempertimbangkan kontribusi perilaku etis terhadap konflik peran maupun kepuasan kerja sehingga konlik peran tidak mempengaruhi kepuasan kerja wiraniaga. Wiraniaga bekerja berdasarkan motivasi hirarkis yang dimulai dari tahap fisik sampai aktualisasi diri, wiraniaga mengutamakan tahap fisik (kebutuhan sandang dan pangan), dan keamanan (safety) sebelum pada tahap sosial.

\section{PENUTUP}

Berdasarkan analisis data diperoleh simpulan sebagai berikut: 1) Kompensasi, dan peng- awasan, berpengaruh signifikan terhadap perilaku etis wiraniaga yang berarti hipotesis yang diajukan dalam penelitian ini benar. Pengaruh positif kompensasi dan pengawasan menunjukkan semakin tinggi kompensasi, dan pengawasan wiraniaga maka semakin tinggi orientasi wiraniaga untuk berperilaku secara etis. Kompensasi merupakan pemicu langsung yang memotivasi perilaku individu dalam mencapai tujuan perusahaan. Dengan pengawasan, kesempatan bagi wiraniaga untuk berperilaku tidak etis menjadi kecil karena wiraniaga mempertimbangkan konsekuensi dari perilaku tidak etisnya. 2) Perilaku etis wiraniaga mempengaruhi konflik peran dan kinerja namun tidak mempengaruhi kepuasan kerja wiraniaga. Dengan demikian semakin tinggi perilaku etis wiraniaga maka semakin rendah konflik peran yang dirasakan, serta semakin tinggi kinerja wiraniaga. Seorang wiraniaga memiliki kewajiban untuk memenuhi harapan konsumen dan perusahaan, namun hal tersebut sering bertentangan sehingga timbul konflik peran dalam diri wiraniaga. Saat wiraniaga tidak berperilaku etis, maka konsumen akan menolak pembelian karena memiliki image negatif pada produk yang ditawarkan. Wiraniaga yang sukses memiliki orientasi pada konsumen dan membangun kepercayaan dari konsumen. Dengan membangun hubungan dengan konsumen melalui perilaku etis akan meningkatkan transaksi sehingga kinerja wiraniaga akan meningkat. Dengan demikian dapat disimpulkan wiraniaga yang berorientasi etis, kinerjanya akan meningkat sebagai dampak dari hubungan jangka panjang dengan konsumen

Berdasarkan hasil analisis ditemukan faktor dominan yang mempengaruhi perilaku etis wiraniaga adalah pengawasan, dengan demikian pemasar dapat meningkatkan orientasi perilaku etis wiraniaga melalui pengawasan seperti pengawasan atasan serta memberikan sanksi bagi pelanggaran etika dalam penjualan. Pemasar juga perlu melakukan edukasi etika bagi wiraniaga agar lebih berorientasi etis dalam bekerja seperti pelatihan-pelatihan maupun seminar etika dalam bisnis dan pemasaran.

Penelitian ini tidak lepas dari beberapa keterbatasan penelitian. Keterbatasan dalam penelitian ini berupa persepsi responden tergantung pada pemahaman butir pertanyaan yang tercantum dalam kuesioner sehingga 
kemungkinan terjadi perbedaan persepsi responden dengan pengukuran yang bersifat self reported tanpa dilengkapi dengan metode pengumpulan data lainnya untuk keakuratan data yang diteliti seperti wawancara sehingga kemungkinan terjadi liniency bias. Hasil penelitian ini tidak dapat digeneralisasi karena penelitian dibatasi hanya di perusahaan otomotif di Jawa Tengah. Responden hanya berasal dari bidang otomotif saja. Hal ini akan berdampak pada validitas eksternal yang rendah. Berdasarkan keterbatasan, penulis memberikan saran untuk penelitian selanjutnya menggunakan wiraniaga dari berbagai jenis usaha untuk membandingkan perilaku etis berdasarkan jenis usaha. Selain itu pengumpulan data juga perlu dilengkapi dengan wawancara untuk meminimalisasi self reported.

\section{DAFTAR PUSTAKA}

Abratt, R. and N. Penman. 2002. Understanding factors affecting salespeople's perceptions of ethical behavior in South Africa, Journal of Business Ethics. 35. 269-80.

Beatty, SE., M. Mayer, JE. Coleman, KE. Reynolds and J. Lee. 1996. Customersales associate retail relationships", Journal of Retailing. 72 (3). 223-47.

Boedecker, KA., FW. Morgan and JJ. Stoltman. 1991. Legal dimensions of salesperson's statements: a review and managerial suggestions, Journal of Marketing. 55. 70-80.

Boyle, B. and R. Dwyer. 1995. Power, bureaucracy, influence, and performance: their relationships in industrial distribution channels, Journal of Business Research. 32. 189200.

Chonko, LB. and JJ. Burnett. 1983. Measuring the importance of ethical situations as a source of role conflict: a survey of salespeople, sales managers, and sales support personnel, Journal of Personal Selling \& Sales Management. 3. 41-47.

Churchill, GA., JN. Ford and O.C. Walker Jr .1976. Organizational climate and job satisfaction in the salesforce, Journal of Marketing Research. 13. 323-332.

Cravens, DW., TN. Ingram, RW. LaForge and CE. Young. 1993. Behavior-based and outcome-based salesforce control systems, Journal of Marketing. 57. 4759.

Dubinsky, AJ. and TN. Ingram. 1984. Correlates of salespeople's ethical conflict: an exploratory investigation, Journal of Business Ethics. 3. 343-53.

Herche, J1., MJ. Swenson and W.Verbeke, 1996. Personal Selling Constructs and Measures: Emic Versus Etic Approaches to Cross-National Research, European Journal of Marketing. 30(7). 83-97

Hidayat, A. 2010. Lawfulness attitudes and willingness to buy product counterfeiting. German: Lambert Academic Publshing AG \& Co KG

Honeycutt, ED., JA.Siguaw, and TG. Hunt, 1995. Business ethics and job-related constructs: a cross- cultural comparison of automotive salespeople, Journal of Business Ethics. 14. 235-48.

Hunt, SD. and AZ. Vasquez-Parraga. 1993. Organizational consequences marketing ethics, and salesforce supervision, Journal of Marketing Research. 30. 78-90.

Ingram, TM., RW. Laforge, RA. Avila Jr., CH. Schwepker and MR.Williams. 2001. Professional Selling: A Trust-Based Approach, Hartcourt, Orlando, FL.

Johnston, MW., A. Parasuraman, CM. Futrell and WC. Black. 1990. A longitudinal assessment of the impact of selected organizational influences on salespeople's organizational commitment during early employment, Journal of Marketing Research. 27. 333-344.

Kartasasmita, G. 1997. Etika Dunia Usaha atau Etika Bisnis dalam Pembangunan. Lembaga Studi dan Pengembangan Etika Usaha Indonesia. Jakarta, 25 Agustus. 
Kurland, NB. 1996. Sales agents and clients: ethics, incentives, and a modified theory of planned behavior, Human Relations. 49 (1). 51-74.

Marketing. 2004. Jakarta, Nomor 12/IV/Desember.

MacKenzie, SB., PM. Podsakoffand and M. Ahearne. 1998. Some possible antecedents and consequences of inrole and extra-role salesperson performance, Journal of Marketing. 62. 87-98.

Marchetti, M. 1997. Whatever it takes, Sales \& Marketing Management. 29-38.

Oliver, L.R. and E. Anderson. 1994. An empirical test of the consequences of behavior and outcome-based sales control systems, Journal of Marketing. 58, 53-67.

Purnamasari, V. dan AA. Chrismastuti. 2006. Dampak reinforcement contingency terhadap hubungan sifat machiavellian dan perkembangan moral, SNA 9, Padang

Robertson, DC. and E. Anderson. 1993. Control system and task environment effects on ethical judgment: an exploratory study of industrial salespeople, Organization Science. 4. 61745.

Roman, S. and JL. Munuera. 2005. Determinants and consequences of ethical behaviour: an empirical study of slespeople. European Journal of Marketing. 39 (56).
Roma'n, S. and S. Ruiz. 2005. Relationship outcomes of perceived ethical sales behavior: the customer's perspective, Journal of Business Research, in press.

Schwepker, CH. 2001. Ethical climates relationship to job satisfaction, organizational commitment, and turnover intention in the salesforce, Journal of Business Research. 54. 39-54.

Schiffman, LG., and LL. Kanuk. 2004. Consumer behavior, 8 Ed, New Jersey: Prentice Hall, Inc.

Sekaran, U. 2003. Research Methods for Business: Skill-Building Approach, Fourth Edition, New York: John Wiley \& Sons Inc

Turner, JH. and SR. Valentine. 2001. Cynicism as a fundamental dimension of moral decision-making: a scale development, Journal of Business Ethics. 34. 123-36.

Verbeke, W., C. Ouwerkerk and E. Peelen. 1996. Exploring the contextual and individual factors on ethical decision making of salespeople, Journal of Business Ethics. 15. 1175-87.

Weeks, WA. and J. Nantel. 1992. Corporate code of ethics and sales force behavior: a case study, Journal of Business Ethic. 11. 753-60.

Wotruba, T. 1990. A comprehensive framework for the analysis of ethical behavior, with a focus on sales organisations, Journal of Personal Selling \& Sales Management. 10, 2942 , Spring. 